\title{
Lecture Notes in Physics
}

Edited by J. Ehlers, München, K. Hepp, Zürich, H. A. Weidenmüller, Heidelberg, and J. Zittartz, Köln Managing Editor: W. Beiglböck, Heidelberg

\section{9}

Proceedings of the

Fifth International Conference

on Numerical Methods

in Fluid Dynamics

June 28 - July 2,1976

Twente University, Enschede

Edited by

A. I. van de Vooren and P. J. Zandbergen

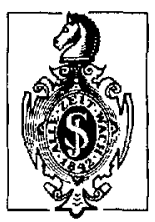

Springer-Verlag

Berlin · Heidelberg · New York 1976 


\section{Editors}

Prof. Dr. Adriaan I. van de Vooren

Mathematics Department

University of Groningen

P.O.Box 800

Groningen/The Netherlands

Prof. Dr. Pieter J. Zandbergen

Department of Applied Mathematics

Technical University Twente

P.O.Box 217

Enschede/The Netherlands

International Conference on Numerical Methods in

Fluid Dynamics, 5th, Twente University of Technology, 1976.

Proceedings of the Fifth Intermational conference

on Numerical Methods in Fluid Dynamics, June 28-July

3, 1976, Twente University of Technology.

(Lecture notes in physics ; 59)

Bibliognaphy: p.

Includes index.

1. Fluid dynamics--Congresses. 2. Numerical

analysis--Congresses. I. Vooren, Adriaan Isak

van de. II. Zandbergen, P. J. III. Series.

QA911.I54 1976 532'.05'015194.

ISBN 3-540-08004-X Springer-Verlag Berlin Heidelberg New York ISBN 0-387-08004-X Springer-Verlag New York Heidelberg Berlin

This work is subject to copyright. All rights are reserved, whether the whole or part of the material is concerned, specifically those of translation, reprinting, re-use of illustrations, broadcasting, reproduction by photocopying machine or similar means, and storage in data banks.

Under $\S 54$ of the German Copyright Law where copies are made for other than private use, a fee is payable to the publisher, the amount of the fee to be determined by agreement with the publisher.

(C) by Springer-Verlag Berlin - Heidelberg 1976

Printed in Germany

Printing and binding: Beltz Offsetdruck, Hemsbach/Bergstr. 


\section{Editors' Preface}

This volume of Lecture Notes in Physics contains the complete proceedings of the Fifth International Conference on Numerical Methods in Fluid Dynamics, which was held at Twente University of Technology, Enschede, the Netherlands from June 28 to July 3, 1976. In the programme two invited one-hour lectures were included, one by prof. J.L. LIONS from the Collège de France in Paris (presented by Prof. R. GLOWINSKI) on those methods for solving free surface problems which are connected to the calculus of variations, and the other by Prof. S.A. ORSZAG from the Mathematics Department of the Massachusetts Institute of Technology, U.S.A., on transition and turbulence. Besides these there were given four invited half-hour lectures, namely by Prof. O.R. BURGGRAF from the Ohio State University, U.S.A., on viscous flows, Dr. M.G. HALL, Royal Aircraft Establishment, England, on transonic flows, Mr. W. LOEVE, National Aerospace Laboratory NLR, the Netherlands, on aerodynamics of wing-body combinations at subsonic speeds and Dr. G. SCHMID, Ruhr University, Germany, on finite element methods in fluid dynamics. Finally, 53 short communications have been presented which are also published in this volume in alphabetic order of the name of the (first) author.

The conference has been financially supported by the Office of Naval Research (ONR) and the Air Force Office of Scientific Research (AFOSR), both in the U.S.A. The Dutch Organizing Committee wishes to express his thanks for this highly appreciated support.

We wish to thank all persons who contributed to the success of the conference, the participants for their scientific contributions and the students of the Drienerlo Organisational Bureau for all technical arrangements and help in the organisation.

Finally, we wish to express our appreciation to Dr. W. BEIGLBÖCK and the Springer Verlag for the rapid publication of these proceedings in the series of Lecture Notes in Physics. 


\section{Contents}

One-hour lectures

LIONS, J.L.: Some Methods of Resolution of Free Surface Problems............

ORSZAG, S.A.: Turbulence and Transition: A Progress Report.............32

Half-hour lectures

BURGGRAF, 0.R.: Some Recent Developments in Computation of Viscous Flows.....52

HALL, M.G.: Methods and Problems in the Calculation of Transonic Flows.....65

LOEVE, W.: The Calculation of Aerodynamic Characteristics of Wing-Body

Combinations at Subsonic Flight Speeds......................75

SCHMID, G.: Ritz-Galerkin Approximations in Fluid Dynamics.............84

\section{Communications}

BAZZHIN, A.P. and MIKHATLOV, Yu.Ya.: On Computations of Supersonic Flows around Blunt Bodies with Combined Cross Sections..................96

BECKUM, F.P.H. van: Two Coordinate Systems Description of Viscous Flow past a Circular Cylinder................................101

BELOTSERKOVSKII, O.M. and YANITSKII, V.E.: Numerical Investigation of Rarefied Gas Flows by a Statistical Particle-in-Cel1 Method............107

BURSTEIN, S. and TURKEL, E.L.: Eulerian Computations in Domains with Moving Boundaries.....................................114

CHILDRESS, S. and PEYRET, R.: Convection Induced by Motile Particles......123

CHORIN, A.J.: A Random Choice Method in Gas Dynamics.................129

CHOW, R. and MELNIK, R.E.: Numerical Solutions of the Triple-Deck Equations

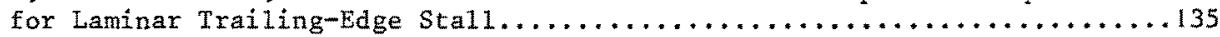

CHU, C.W. and NADTR $S$, : Unsteady Two-Dimensional Subsonic, Transonic and Supersonic Flow Calculations by the Method of Characteristics.......145

DALY, B.J.: Pulsatile Flow through a Tube Containing Rigid and Distensible

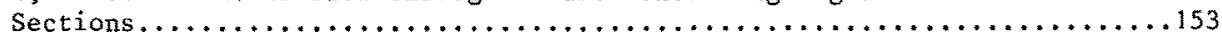

DEIWERT, G.S.: Recent Computation of Viscous Effects in Transonic F1ow......159

DENNIS, S.C.R.: A Numerical Method for Calculating Steady Flow past a

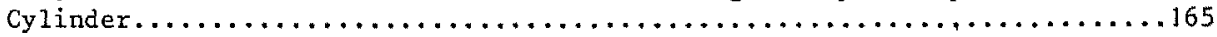

DICKSON, L.J., CHEN, A.W. and RUBBERT, P.E.: A New Approach to Far-Field Boundary Conditions in Transonic Computations .................

DWYER, H.A., PETERSON, T. and BREVER, J.: Sensitivity Analysis Applied to Boundary Layer Flow................................... 179 
ECER, A.: A Modal. Analysis for the Finite Element Solution of Navier-

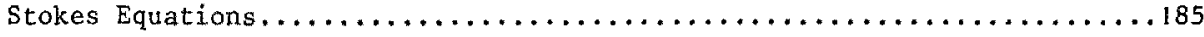

GANOULIS, J. and THIRRIOT, C.: Numerical Simulation of Laminar

Separated Flow between Periodically Varied Walls.................191

GHIA, U., GHIA, K.N, and STUDERUS, C.J.: Use of Surface-Oriented Coordinates in the Numerical Simulation of Flow in a Turbine Cascade............197

GLOWINSKI, R., PERLAUX, J. and PIRONNEAU, O.: Use of optimal Control Theory for the Numerical Simulation of Transonic Flow by the Method of Finite Elements................................205

GOSMAN, A.D., LI, K.H. and SAMARAWEERA, D.S.A.: A Numerical Calculation Procedure for Two phase Recirculating Flows...................212

GROSSMAN, B. and MELNIK, R.E.: The Numerical Computation of the Transonic

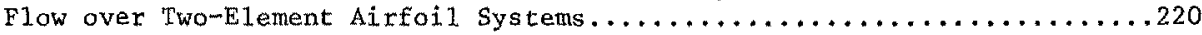

HAFEZ, M.M. and CHENG, H.K.: An Acceleration Technique Related to Wynn's $\varepsilon-A l g o r i t h m$ with Application to Transonic Flow Calculations......228

HERBERT, Th.: Periodic Secondary Motions in a Plane Channe1............235

ISRAELI, M. and ORSZAG, S.A.: Numerica1 Investigation of Viscous Effects on Trapped Oscillations in a Rotating Fluid.......................

JOHNSON, F.T., EHLERS, F.E. and RUBBERT, P.E.: A Higher Order Dane1 Method for General Analysis and Design Applications in Subsonic Flow....247

JONES, D.J.: Computation of Bow Shocks in Transonic Flow.............254

KARLSSON, K.R. and SEOTN, Y.C-J.: The Method of Decomposition Applied in

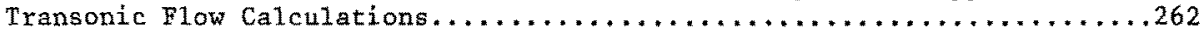

KOROBEINIKOV, V.P., CHUSHKIN, P.I., SHIDLOVSKAYA, L.V. and SHURSHALOV, L.V.: The Modelling and Calculation of Some Cosmic Phenomena of Blast Type....268

LENOIR, M.: Numerical Simulation of the Collapse of a Cavitation Bubble. ...274

LEONARD, A.: Simulation of Three-Dimensional Separated Flows with Vortex Filaments..........................................280

LI, C.D.: A Mixed Explicit-Implicit Splitting Methad for the Compressible Navier-Stokes Equations...............................285

LINDROOS, M. and LAINE, S.: Numerical Solutions of the Navier-Stokes Equations for Unsteady Boundary-Layer Flows past a Wavelike Bulge on a Flat Plate.............................................. 293

LIU, N.: Finite Difference Solution of the Navier-Stokes Equations for Incompressible Three-Dimensional Internal Flows................. 300

MACCORMACK, R.W.: A Rapid Solver for Hyperbolic Systems of Equations.......307

MARSHALL, $G$, and MOLEDO, L.: Computational Aspects of Viscous Incompressible Fluids, II. ...................................... 318

MODARRESS, D. and HOLT, M.: Laminar Boundary-Layer Solutions in Three Dimensions. . . . . . . . . . . . . . . . . . . . . . . . . . . . . . 324 
NOH, W.F. and WOODWARD, P.: SLIC (Simple Line Interface Calculation)...

PANDOLFI, M.: Supersonic Flow about Elliptic Cones with Large Semi-axis Ratio............................................. 34

RIZZI, A, and BAILEY, H.: Finite-Volume Solution of the Euler Equations for Steady Three-Dimensional Transonic Flow...................... 347

ROESNER, K.G.: Separation Phenomena in Two-Dimensional Channel Flow.........353

RoUx, J.: Résolution Numêrique d'un Problème d'Ecoulement Subsonique de Fluides Compressibles.................................... 360

RUBIN, S.G, and KHOSLA, P.K.: Numerical Methods Based on Polynomial Spline Interpolation........................................... 370

RUSANOV, V.V.: Some Properties of Difference Schemes of Third-Order

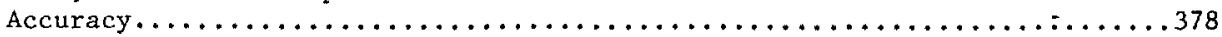

SANDERS, B.R. and DWYER, H.A.: Numerical Modeling of Unsteady Flow Fields wi th Detonation............................................. 384

SCHIFF, L.B.: A Numerical Solution of the Axisymetric Jet Counterflow

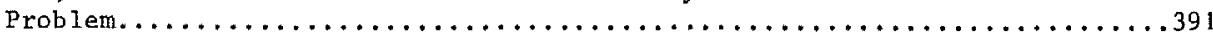

SCHUMANN, U. and SWEET, R.A.: Direct Poisson Equation Solver for Potential and Pressure Fields on a Staggered Grid with Obstacles................ 398

SHESTAKOV, A.I.: Numerical Solution of the Navier-Stokes Equations at High

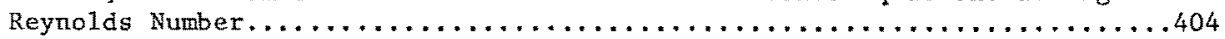

SHOKIN, Yu.I.: Analysis of the Properties of Approximation Viscosity of Difference Schemes by Means of the Method of Differential Equations......410

STEPPELER, J.: Physical Instability and Weather Prediction - Two Examples Using a Finite Difference Scheme............................... 415

THOMPSON, J.F., THAMES, F.C., HODGE, J.K., SHANKS, S.P., REDDY, R.N. and MASTIN, C.W.: Solutions of the Navier-Stokes Equations in Various Flow Regimes on Fields Containing Any Number of Arbitrary Bodies Using Boundary-Fitted Coordinate Systems.

VANDERBORCK, G. and PLATTEN, J.K.: On a Rather General Computer Program for Testing the Linear Stability of Various Velocity Profiles..........428

VIVIAND, H. and GRAZZI, W.: Numerical Solution of the Compressible Navier-Stokes Equations at High Reynolds Numbers with Applications to

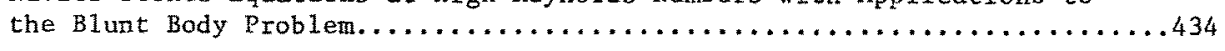

WALKDEN, F. and EVANS, D.: On the Detection of Shock Waves in Steady Twoor Three-Dimensional Supersonic Gas Flows....................... 440

WU, J.C. and WAHBAH, M.M.: Numerical Solution of Viscous Flow Equations Using Integral Representations................................ 448

YANENKO, N.N., KROSHKO, E.A., LISEIKIN, V.V., FOMIN, V.M., SHAPEEV, V.P. and SHITOV, Yu.A.: Methods for the Construction of Moving Grids for Problems of Fluid Dynamics with Big Deformations..................... 454 